\title{
A cross-sectional, multicenter, observational study to assess the prophylaxis of venous thromboembolism in Lebanese and Jordanian hospitals
}

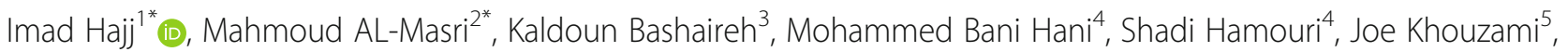
Nisrine Sabra ${ }^{5}$ and Chahine Fadel ${ }^{5}$

\begin{abstract}
Background: There is a growing body of evidence showing substantial underuse of appropriate venous thromboembolism (VTE) prophylaxis in patients at risk. In the present study, our goal was to assess the current practices in the use rate of VTE prophylaxis among hospitalized patients in Jordan and Lebanon.

Methods: A cross-sectional, multicenter, observational study was conducted on 40 centers across Lebanon and Jordan. We included patients who were admitted to the participating hospitals for the treatment of a serious medical or surgical illness. The patients' records were screened for the fulfillment of inclusion/exclusion criteria during a single assessment visit. The proportion of medical and surgical patients who were at risk of VTE and the thrombo-prophylactic measures employed by physicians for these patients were assessed according to the American College of Chest Physicians (ACCP 2016) guidelines.

Results: The present study included 704 patients (400 from Jordan and 304 from Lebanon) with a mean age of $54.9 \pm 17.5$ years. Almost $59 \%$ of the patients received prophylaxis treatment in form of pharmacological anticoagulant prophylaxis and/or mechanical prophylaxis. Low molecular weight heparin was the most commonly used anticoagulant for VTE prophylaxis in 366 out of the total 704 (51.9\%) patients in the analysis cohort. Two hundred and sixteen patients (52, 95\% confidence interval [47.1-56.9\%]) received appropriate prophylactic agents out of 415 patients who were eligible for prophylaxis according to the ACCP 2016 guidelines. On the other hand, 199 (72.1, 95\% confidence interval [66.4-77.3\%) patients received prophylaxis out of 276 ineligible patients. The rate of compliance to guidelines showed wide variations according to the type of hospital, specialty, and the patients' age. The multivariate logistic regression analysis showed that only age was a significant predictor of appropriate VTE prophylaxis (odds ratio [OR] 1.05, $P<0.001$ ).

Conclusion: The rates of the appropriate use of VTE prophylaxis are low in Lebanon and Jordan. There is a lack of compliance to guidelines for VTE prophylaxis use for hospitalized patients in both countries.
\end{abstract}

Keywords: Venous thromboembolism, VTE prophylaxis, ACCP guideline

\footnotetext{
* Correspondence: iphaj@@stgeorgehospital.org; malmasri@khcc.jo

'Department of Surgery, Saint George Hospital University Medical Center,

Ashrafiyeh, Beirut, Lebanon

${ }^{2}$ Department of Surgery, King Hussein Cancer Center, PO Box 1269,

Al-Jubeiha, Amman 11941, Jordan

Full list of author information is available at the end of the article
}

(c) The Author(s). 2021 Open Access This article is licensed under a Creative Commons Attribution 4.0 International License, which permits use, sharing, adaptation, distribution and reproduction in any medium or format, as long as you give appropriate credit to the original author(s) and the source, provide a link to the Creative Commons licence, and indicate if changes were made. The images or other third party material in this article are included in the article's Creative Commons licence, unless indicated otherwise in a credit line to the material. If material is not included in the article's Creative Commons licence and your intended use is not permitted by statutory regulation or exceeds the permitted use, you will need to obtain permission directly from the copyright holder. To view a copy of this licence, visit http://creativecommons.org/licenses/by/4.0/. The Creative Commons Public Domain Dedication waiver (http://creativecommons.org/publicdomain/zero/1.0/) applies to the data made available in this article, unless otherwise stated in a credit line to the data. 


\section{Introduction}

Venous thromboembolism (VTE) is a life-threatening disorder and a major cause of morbidities and mortality among hospitalized patients [1]. The condition is characterized by the development of thrombosis of deep veins of the leg or pelvis (DVT) that propagate to the pulmonary circulation leading to pulmonary embolism (PE) [2]. According to previous epidemiological studies, VTE is the third most common cardiovascular disease with reported incidence rates of 130 and 100 per 100,000 persons every year for men and women, respectively [3]. Old age, obesity, prolonged immobility, acute heart failure, malignancy, hyperestrogenemia, and genetic susceptibility are major risk factors for VTE development [4]. Hospitalized patients are at increased risks of VTE due to the presence of multiple risk factors that are usually cumulative [5]. Despite that VTE has been previously described as a complication of major surgery, recently published evidence shows that hospitalized patients with a medical illness have comparable risks of VTE to that of the patients undergoing major surgery [6]. Previous reports demonstrated that up to $20 \%$ of hospitalized medical patients are expected to develop VTE during hospital stay [7]. VTE is a major cause of mortality in hospitalized patients as well; up to $10 \%$ of fatality cases during hospitalization were attributed to VTE in autopsy-based studies [8]. Therefore, effective VTE prophylaxis among hospitalized at-risk patients, either surgical or medical, is critical in improving patients' outcomes and survival [9].

Anticoagulants represent the cornerstone for VTE prophylaxis among hospitalized patients [10]. Historically, unfractionated heparin (UFH) was the anticoagulant of choice for VTE prophylaxis; however, the current body of evidence shows that low molecular weight heparin (LMWH) has a comparable efficacy profile, with more favorable safety data than UFH [11]. The American College of Chest Physicians (ACCP 2012) guidelines recommend using prophylactic anticoagulants in cases with a high risk of VTE [12]. They recommend using parenteral LMWH or fondaparinux as a first choice for VTE prophylaxis over IV UFH in the cases of acute deep venous thrombosis (DVT) or pulmonary embolism (PE). They also recommend using thrombolytic therapy in case of PE with hypotension. The guidelines also stated that, in cases of surgically provoked PE or DVT, 3 months of anticoagulant therapy is recommended. Also in the case of PE or DVT that is associated with active cancer, they recommend using LMWH therapy over vitamin $\mathrm{K}$ antagonist (warfarin). For extensive superficial vein thrombosis, they recommend a prophylactic therapy with fondaparinux or LMWH instead of no anticoagulants use, and they recommend fondaparinux over LMWH. Other treatment options as compression stockings were recommended to prevent postthrombotic syndrome. Therefore, LMWH and fondaparinux are currently the first-line prophylaxis options in hospitalized patients [13]. Although multiple international guidelines recommend the use of VTE prophylaxis for at-risk hospitalized patients, the rates of prophylaxis strategies implementation are not satisfied in many regions [9]. The ENDORSE study reported that less than $40 \%$ of hospitalized medical patients receiving appropriate prophylaxis, with great variations in prophylaxis use between countries, regions, and hospitals [7].

The burden of VTE is presumably high among hospitalized patients from the Middle East region [14], as many countries from the region are listed among the top ten countries with the highest rate of non-communicable diseases, such as obesity, hypertension, and diabetes $[15,16]$. In the AVAIL ME study [14], the rate of patients at a very high-risk for VTE was $40.9 \%$ in Iran, 32.7\% in Jordan, 27.7\% in Saudi Arabia, and 30,7 in Lebanon compared to only $16.7 \%$ in Azerbaijan. In the united states of America (USA), VTE is considered a major health problem as nearly 2 million new cases are reported every year with over 600,000 deaths from PE [17]. According to recent reports, the overall compliance with international guidelines concerning VTE prophylaxis was nearly 38\% in the Middle Eastern countries, with wide geographical disparity [14]. In comparison to the countries included in the ENDORSE study [7]; the compliance to VTE prophylaxis guidelines was $68 \%$ in the USA, $54 \%$ in India, $55 \%$ in Kuwait, $81 \%$ in Germany, 60\% in France, 34\% in Egypt, $50 \%$ in Algeria, and 31\% in Argentina [18]. However, the data on the degree of compliance with the current antithrombotic guidelines in the Middle East region is still scarce $[19,20]$. Therefore, in this study, we aimed to assess the current practices of VTE prophylaxis among hospitalized patients in Jordan and Lebanon.

\section{Patients and methods}

We followed the STROBE (Strengthening the Reporting of Observational Studies in Epidemiology Statement) guidelines (Supplementary file no.1) during the preparation of this manuscript [21]. The present study runs in concordance with the principles of the declaration of Helsinki and applicable local regulatory laws. Written informed consent was obtained from every eligible patient, or their relatives, prior to the study's enrollment.

\section{Study design and setting}

We conducted a multicenter, observational, crosssectional study across Lebanon and Jordan hospitals through the period from October 2017 to October 2018. Participating physicians from 40 centers across both counties were randomly selected and asked to recruit eligible patients consecutively. The selection process of the 
participating physicians was stratified according to the type of hospital, specialties, and geographical area.

\section{Participants}

Adults' patients ( $\geq 40$ years old for medical patients and $\geq 18$ years old for surgical patients) of both sexes, who were admitted to any of the participating centers for serious medical illness or surgical indication, were included. We excluded patients with current or recent (1 month before the study) deep venous thrombosis or pulmonary embolism, history of intake of anticoagulant for another co-morbidity in the last month before study's enrollment, weight below $40 \mathrm{~kg}$ or above $100 \mathrm{~kg}$, impaired kidney or liver functions, concomitant participation to a clinical, or missing hospital chart. Pregnant or lactating women were excluded as well.

\section{Sample size calculation and sampling methods}

The primary outcome of the present study was the percentage of patients eligible for VTE prophylaxis who are receiving appropriate prophylaxis treatment. According to the AVAIL ME study, the reported that the overall rate of VTE prophylaxis use in the Middle East among eligible patients was $47.8 \%$ for medical patients and $60 \%$ for surgical patients; while the rate of compliance to ACCP guidelines was only 36\% [22]. Thus, was assumed that $40 \%$ of the eligible patients for VTE prophylaxis are actually receiving appropriate prophylaxis treatment globally. With a margin of error of $3.6 \%$ and a $95 \%$ confidence interval, we calculated that the required sample size will be 700 patients.

The present study utilized a non-probability, consecutive, sampling technique to recruit eligible patients. Investigators were asked to recruit consecutive eligible patients and each selected physician included about 10 to 20 patients who met the inclusion criteria per consulting session.

\section{Data collection and study's outcomes}

The following data were collected from every eligible patient: demographic characteristics, anthropometric measures (weight, height, and body mass index [BMI]), cause of hospital admission, length of hospital stay, type and duration surgery for surgical patients, risk factors for VTE, type and frequency of VTE prophylaxis, and eligibility for VTE prophylaxis according to the ACCP 2016 guidelines [23].

The primary outcome of the present study was the percentage of patients receiving appropriate VTE prophylaxis among the patients eligible for prophylaxis. The secondary outcomes were the rate of patients receiving prophylaxis treatment without being eligible for such treatment as per the guideline, the profile of the medically ill and surgical hospitalized patients and their
VTE risk, the compliance rate of VTE prophylaxis in the different specialties/type of surgery, VTE prophylaxis differences between different regions and geographies, and the predictive factors or barriers for appropriate prophylaxis.

\section{Statistical methods}

All variables recorded during the study were summarized. Frequencies and percentages (with 95\% confidence interval $[\mathrm{CI}]$ for the primary endpoint) were provided for categorical variables. Mean and standard deviation were provided for continuous variables. The analysis was stratified by type of patient (surgical vs. medical), type of surgery, country, and specialty of the doctors. Multivariate logistic regression models were conducted using the baseline factors to assess their effect as predictors of the appropriate use of VTE prophylaxis. A $p$-value of less than $5 \%$ was considered statistically significant. All statistical tests were performed using SPSS program version 25 (IBM, Armonk, NY, USA).

\section{Results}

The present study screened 705 patients from 40 sites across Lebanon and Jordan. Of them, 704 patients (400 from Jordan and 304 from Lebanon) (99.9\%) were eligible for final analysis and one patient $(0.1 \%)$ was excluded as the weight was above $100 \mathrm{~kg}$. Regarding the demographic characteristics of the included patients, the patients' age ranged from 18 to 93 years with a mean age of $54.9 \pm 17.5$ years. Almost $48 \%$ of the patients were males. The mean weight and height of the included patients were $75.7 \pm 13.4 \mathrm{~kg}$ and $165.9 \pm 9.3 \mathrm{~cm}$, respectively. The BMI of the included patients ranged from 16.1 to $44.2 \mathrm{~kg} / \mathrm{m}^{2}$ with a mean BMI of $27.5 \pm 4.8 \mathrm{~kg} / \mathrm{m}^{2}$. In terms of vital signs, the mean SBP and DBP of the included patients were $124.1 \pm 15.4$ and $73.8 \pm 9.7 \mathrm{mmHg}$, respectively. Sixty percent of the patients had one or more current medical conditions. The most commonly encountered medical condition was hypertension (34.8\%), followed by diabetes mellitus $(22.6 \%)$ and coronary artery disease (10.1\%). Two-hundred and forty-six (34.9\%) patients were admitted for medical causes only, $449(63.8 \%)$ patients were admitted for surgical causes only, and $9(1.3 \%)$ patients were admitted for both medical and surgical causes. The average hospital stay of the included patients was $5.8 \pm 8.4$ days. The Demographic and clinical characteristics of the included patients were summarized in Table 1.

Six hundred and sixteen patients (87.5\%) had one or more risk factors for VTE which were either surgical (55.5\%), medical (31.4\%), or surgical and medical risk factors $(0.6 \%)$. Sixty patients $(8.5 \%)$ had risk factors associated with increased bleeding such as active bleeding (1.1\%) and low platelet count. In addition, 25 (3.5\%) 
Table 1 Demographic and clinical characteristics of the participants at baseline

\begin{tabular}{|c|c|}
\hline Variables & $\begin{array}{l}\text { Patients } \\
(N=704)\end{array}$ \\
\hline Age in years, mean $(S D)$ & $54.96(17.5)$ \\
\hline Male, No. (\%) & $340(48.3 \%)$ \\
\hline Weight in $\mathbf{k g}$, mean (SD) & $75.72(13.4)$ \\
\hline Height in $\mathbf{c m}$, mean (SD & $165.96(9.3)$ \\
\hline BMI in $\mathbf{k g} / \mathbf{m}^{2}$, mean (SD) & $27.47(4.8)$ \\
\hline Systolic blood pressure in $\mathbf{m m H g}$, mean (SD) & $124.1(15.4)$ \\
\hline Diastolic blood pressure in $\mathbf{m m H g}$, mean (SD) & $73.75(9.7)$ \\
\hline Pulse rate in beat/min, mean (SD) & $81.38(12.5)$ \\
\hline Temperature in C, mean (SD) & $36.87(0.46)$ \\
\hline Hypertension, No. (\%) & $245(34.8)$ \\
\hline Diabetes, No. (\%) & $159(22.6)$ \\
\hline History of other chronic illness, No. (\%) ${ }^{a}$ & $503(71.4)$ \\
\hline \multicolumn{2}{|l|}{ Cause of admission, No. (\%) } \\
\hline - Medical Causes & $246(34.94 \%)$ \\
\hline - Surgical Causes & $449(63.78 \%)$ \\
\hline - Medical and Surgical Causes & $9(1.28 \%)$ \\
\hline \multicolumn{2}{|l|}{ Type of Surgery, No. (\%) } \\
\hline - Open & $327(46.45 \%)$ \\
\hline - Laparoscopic & $131(18.61 \%)$ \\
\hline Hospital Stay in days, mean (SD) & $5.83(8.4)$ \\
\hline \multicolumn{2}{|l|}{ Risk factors for VTE, No. (\%) } \\
\hline - Surgical risk & $391(55.5 \%)$ \\
\hline - Medical risk & $221(31.4 \%)$ \\
\hline - Medical and surgical risk & $4(0.6 \%)$ \\
\hline \multicolumn{2}{|l|}{ Surgical risk factors for VTE, No. (\%) } \\
\hline - Obesity & $237(33.7)$ \\
\hline - Age $>60$ years old & $117(16.7 \%)$ \\
\hline - Laparoscopic Surgery (> 45 Min) & $59(8.38)$ \\
\hline - Other factors ${ }^{a}$ & $523(74.3)$ \\
\hline \multicolumn{2}{|l|}{ Degree of surgical risk factors for VTE, No. (\%) } \\
\hline - Low & $162(23.1)$ \\
\hline - Moderate & $109(15.48)$ \\
\hline - High & $86(12.22)$ \\
\hline - Highest & $38(5.4)$ \\
\hline \multicolumn{2}{|l|}{ Medical risk factors for VTE, No. (\%) } \\
\hline - Elderly Age ( $\geq 70$ Years) & $94(13.35)$ \\
\hline - Reduced Mobility (At Least 72 h) & $93(13.2)$ \\
\hline - Obesity & $86(12.22)$ \\
\hline - Other factors & $181(25.7 \%)$ \\
\hline Risk factors associated with increased bleeding, №. (\%) & $60(8.5)$ \\
\hline
\end{tabular}

VTE Venous thromboembolism, SD Standard deviation

a Patient may have more than one chronic condition patients had risk factors associated with mechanical prophylaxis which were severe peripheral arterial disease $(0.4 \%)$, congestive heart failure $(2.8 \%)$, and acute superfi$\mathrm{cial} /$ deep vein thrombosis $(0.3 \%)$.

Among the 704 patients who were eligible for the final analysis, 415 (58.9\%) patients received prophylaxis treatment in form of pharmacological anticoagulant prophylaxis $(n=371,52.7 \%)$ mechanical prophylaxis $(n=13,1.8 \%)$, and pharmacological plus mechanical prophylaxis $(n=31,4.4 \%)$. LMWH was the most commonly used anticoagulant for VTE prophylaxis $(n=366)$; however, the unfractionated heparin was administrated in 56 patients only as seen in Table 2. In Lebanon as well as Jordan, LMWH was the most commonly used anticoagulant for VTE prophylaxis $(N=192,48 \%)$ and $(N=174,57.2 \%)$, respectively (Table 3 ).

Among surgical patients who received anticoagulants $(N=233), 59.2 \%$ of them received the drug preoperatively and $40.3 \%$ received it postoperatively. Only $6.3 \%$ of the patients received mechanical prophylaxis in the form of graduated compression stockings or intermittent pneumatic compression. Almost 31\% of the patients continued anticoagulants treatment after discharge in the form of LMWH (85.9\%), aspirin (10.2\%), warfarin (3.1\%), and Fondaparinux (0.8\%).

Among the total 704 eligible patients, 415 (58.9\%) patients received VTE prophylaxis, while 289 (41.1\%) did not receive prophylaxis. For those who received VTE prophylactic treatment, 216 (52, 95\% CI [47.1-56.9\%) received appropriate prophylactic agents according to ACCP guidelines. For those who were not treated with prophylactic agents, 212 (73.4, 95\% CI [67.9-78.4\%) were eligible for VTE prophylaxis according to ACCP guidelines as presented in Table 4.

About $60.9 \%$ (95\% CI 51.9-69.4\%) of the patients ( $n=$ 78) received VTE prophylaxis out of the medical patients who were eligible for prophylaxis according to ACCP 2016 guideline $(n=128)$. While in surgical patients, only $45.1 \%$ (95\% CI $39.3-51 \%)$ of the patients $(n=133)$ received VTE prophylaxis out of those who were eligible for prophylaxis $(n=295)$, Fig. 1 . All patients with combined medical and surgical conditions received appropriate prophylaxis.

Regarding the orthopedic surgery, most of the patients received appropriate VTE prophylaxis according to ACCP 2016 guideline. While in non-orthopedic surgery, the number of patients who received appropriate VTE prophylaxis $(N=170)$ was lower than the number of patients who were eligible for prophylaxis $(N=227)$ as seen in Fig. 2.

The supplementary file no.2 shows the distribution of appropriate VTE prophylaxis according to doctors' specialty and the type of surgery. 
Table 2 VTE prophylaxis/treatment of the included patients

\begin{tabular}{ll}
\hline Variables & $\begin{array}{l}\text { Patients } \\
(\mathbf{N}=\mathbf{7 0 4})\end{array}$ \\
\hline No. of patients received prophylaxis, No. (\%) & $415(58.9)$ \\
- Pharmacological anticoagulant prophylaxis & $371(52.7)$ \\
- Mechanical prophylaxis & $13(1.8)$ \\
- Pharmacological and Mechanical prophylaxis & $31(4.4)$ \\
Types of anticoagulant, No. (\%) & \\
- LMWH & $366(51.9)$ \\
- Unfractionated Heparin & $56(7.9)$ \\
Timing of anticoagulants for surgical patients, No. (\%) & \\
- Preoperatively & 138 \\
& $(59.23)$ \\
- Postoperatively & $94(40.34)$ \\
- Preoperatively/ Postoperatively & $1(0.43)$ \\
No. of patients continued prophylaxis after discharge, & 128 \\
No. (\%) & $(30.84)$ \\
Duration of LMWH after discharge, mean (SD) & 17.58 \\
& $(80.9)$ \\
Duration of Warfarin after discharge, mean (SD) & $28(16.2)$ \\
Concomitant treatment No. (\%) & 460 \\
& $(65.34)$ \\
\hline LWH Low molecular weight heparin, SD Standard deviation
\end{tabular}

LMWH Low molecular weight heparin, SD Standard deviation

Overall, the rate of compliance to ACCP guidelines was higher in private hospitals than in public hospitals ( $85 \%$ versus $57.8 \%$, respectively). The rate of compliance to ACCP guidelines was higher among oncologists (73.3\%) and general family specialists (72\%) than other specialized doctors. The rate of compliance was higher among cases of orthopedic surgeries (100\%) and oncological surgeries $(79 \%)$ than other types of surgery as presented in Table 5.

The multivariate logistic regression analysis showed that only age was a significant predictor of appropriate VTE prophylaxis in the present study (OR 1.05, 95\% CI [1.04-1.07], $P<0.001$ ) (Table 6).

\section{Discussion}

There is a growing body of evidence that shows substantial underuse of VTE prophylaxis in patients at risk [7]. However, the extent of VTE prophylaxis underuse in the Middle East is unclear. In the present observational,

Table 3 VTE prophylaxis differences according to the included countries

\begin{tabular}{lll}
\hline Variables, No (\%) & $\begin{array}{l}\text { Jordan } \\
(\boldsymbol{N}=\mathbf{4 0 0 )}\end{array}$ & $\begin{array}{l}\text { Lebanon } \\
(\boldsymbol{N}=\mathbf{3 0 4})\end{array}$ \\
\hline LMWH & $192(48.0 \%)$ & $174(57.2 \%)$ \\
Unfractionated Heparin & $30(7.5 \%)$ & $28(9.2 \%)$ \\
Other Anticoagulants & $3(0.8 \%)$ & $1(0.3 \%)$ \\
Mechanical Prophylaxis & $12(3.0 \%)$ & $32(10.5 \%)$ \\
\hline
\end{tabular}

LMWH Low molecular weight heparin
Table 4 Appropriate VTE prophylaxis according to ACCP guidelines

\begin{tabular}{llll}
\hline Variables, No (\%) & $\begin{array}{l}\text { Eligible for } \\
\text { prophylaxis }^{\mathbf{a}}\end{array}$ & $\begin{array}{l}\text { Not Eligible for } \\
\text { prophylaxis }^{\mathbf{a}}\end{array}$ & Total \\
\hline $\begin{array}{l}\text { Received } \\
\text { prophylaxis }\end{array}$ & $216(30.68 \%)$ & $199(28.27 \%)$ & 415 \\
$\begin{array}{l}\text { Not received } \\
\text { prophylaxis }\end{array}$ & $212(30.11 \%)$ & $77(10.94 \%)$ & $289.95 \%)$ \\
Total & $428(60.79 \%)$ & $276(39.21 \%)$ & $\begin{array}{l}704 \\
(100 \%)\end{array}$ \\
\hline according to ACCP guidelines & &
\end{tabular}

multinational, study, we found that the rates of the appropriate use of VTE prophylaxis were 60.93 and $45.08 \%$ of the medical and surgical hospitalized patients, who were eligible for VTE prophylaxis, respectively. Notably, there were wide variations in the rates of the appropriate use of VTE prophylaxis according to the type of hospitals, geographical areas, and the specialty of treating physicians. Finally, in the present study, we observed that the rate of an appropriate VTE prophylaxis according to the ACCP guidelines was increasing with the age of the patients: patients with old age ( $\geq 40$ years) were associated with a higher rate of compliance to ACCP guidelines than young patients ( $<40$ years) $[47.4 \%$ versus $20.5 \%]$. In addition, the multivariate logistic regression analysis showed that only age was a significant predictor of appropriate VTE prophylaxis in the present study (OR 1.05, 95\% CI [1.042-1.07], $P<0.001$ ).

In 2017, Levine and colleagues showed that increasing age (OR $0.97, \mathrm{P}<0.001$ ) of patients and a primary cardiovascular diagnosis $(\mathrm{OR} 0.18, \mathrm{P}<0.001$ ) (chest pain, congestive heart failure, syncope/near-syncope, chronic ischemic heart disease, sinus tachycardia) decreased the likelihood of VTE prophylaxis [24].

The risk of VTE is a 10-fold higher in patients who are hospitalized after trauma, surgery, immobilizing medical illness, or pregnant and puerperal women than the general population. Accordingly, recent clinical guidelines strongly recommend the provision of pharmacological VTE prophylaxis in acutely or critically ill inpatients at risk [23, 25]. However, the present study showed that there is substantial underuse of VTE prophylaxis among hospitalized patients in Lebanon and Jordan; less than two-thirds of eligible medical patients received appropriate prophylaxis, while this rate was even much lower in surgical patients. The rate of appropriate VTE prophylaxis varied across different hospitals, geographical areas, and specialties; while the rate of compliance to ACCP guidelines was as low as $26 \%$ in some hospitals. These findings reflect the lack of standardized protocols for VTE prophylaxis use for hospitalized patients in both countries. Another possible explanation is the wide difference in the nature of 


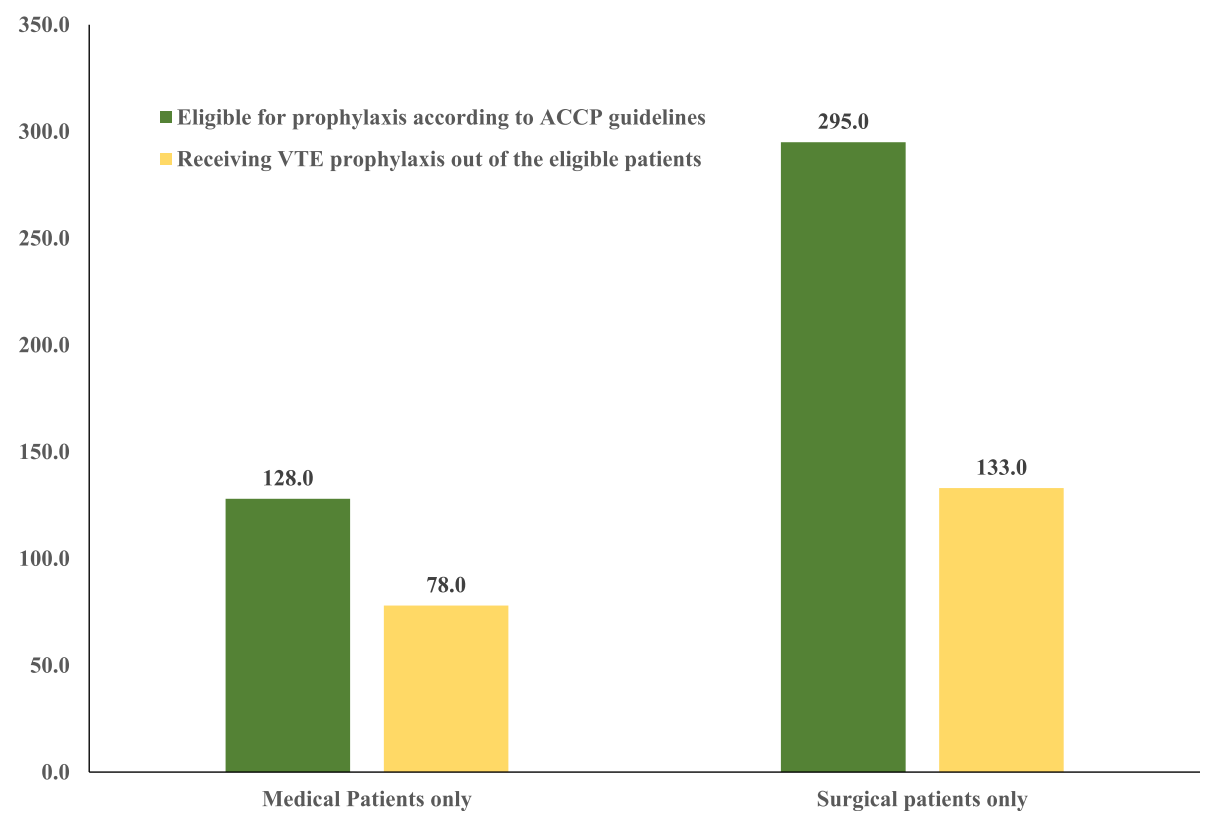

Fig. 1 VTE prophylaxis out of the patients eligible for prophylaxis according to ACCP guidelines. ACCP; American College of Chest Physicians, VTE; venous thromboembolism

participating hospitals; some of them had rural clinics and some of them were university/teaching hospitals. In accordance with our findings, a multicenter study from Lebanon in hospitalized patients reported that the rate of appropriate VTE prophylaxis was $65 \%$ of patients at low risk, $30 \%$ of patients at moderate risk, and $61 \%$ of patients at high risk [19]. A more recent report from
Jordan reported that the rate of appropriate VTE prophylaxis was $67 \%$ in patients admitted to Jordan University Hospital; the study also demonstrated low compliance with the institutional guideline [26]. Other reports showed low rates of appropriate VTE prophylaxis use and guidelines compliance in Saudi Arabia [27] and Iran [28]. The AVAIL ME study reported that the

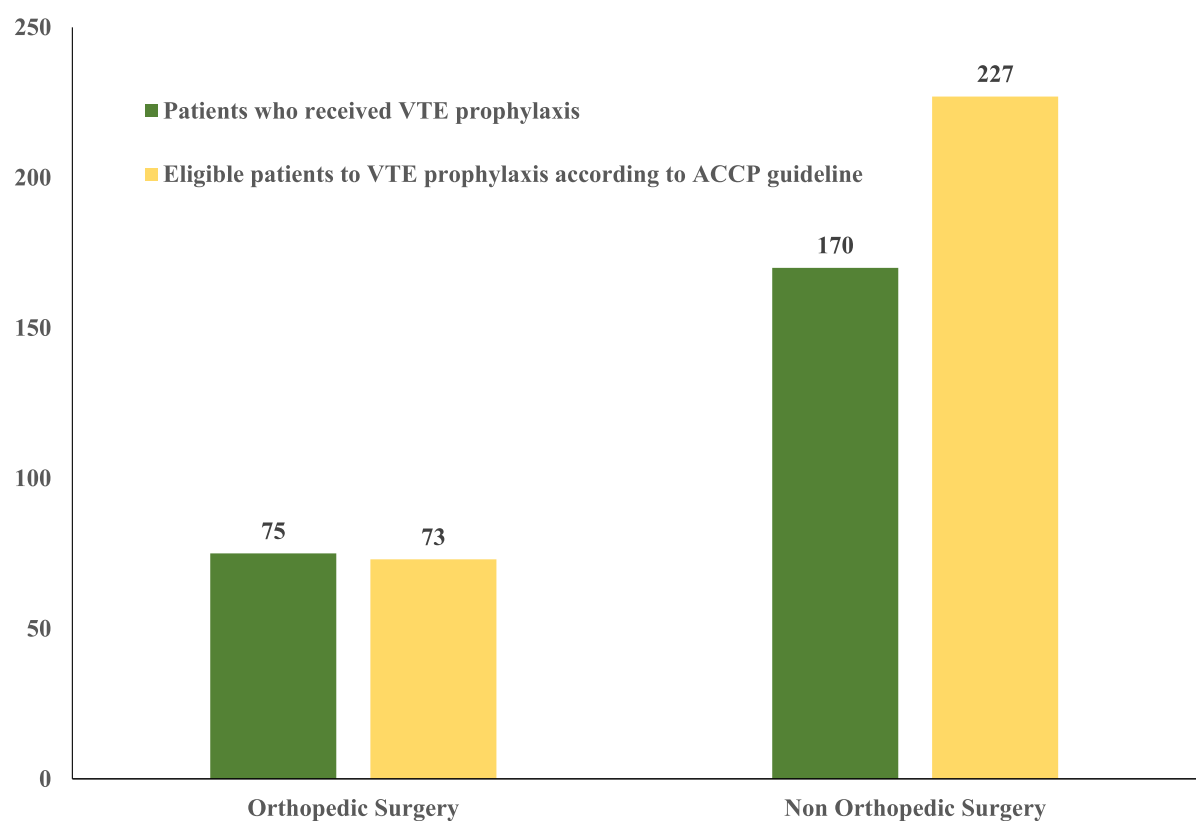

Fig. 2 VTE prophylaxis in surgical patients out of the patients eligible for prophylaxis according to ACCP guidelines. ACCP; American College of Chest Physicians, VTE; venous thromboembolism 
Table 5 Rates of Compliance to ACCP guidelines

\begin{tabular}{|c|c|c|c|}
\hline Variables, No (\%) & Compliant to ACCP guidelines & Not Compliant to ACCP guidelines & Total \\
\hline \multicolumn{4}{|l|}{ Type of hospital } \\
\hline - Private Hospital & $125(85.03)$ & $22(14.97)$ & 147 \\
\hline - Public Hospital & $168(57.8)$ & $22(11.58)$ & 190 \\
\hline Risk Assessment Method implementation & $170(37.86)$ & $279(62.14)$ & 449 \\
\hline \multicolumn{4}{|l|}{ Age of patients } \\
\hline$-\geq 40$ years old & $262(47.4)$ & $291(52.6)$ & 553 \\
\hline$-<40$ years old & $31(20.5 \%)$ & $120(79.5 \%)$ & 151 \\
\hline \multicolumn{4}{|l|}{ Physician Speciality } \\
\hline - Pneumology & $33(47.14)$ & $37(52.86)$ & 70 \\
\hline - Cardiology & $32(40.51)$ & $47(59.49)$ & 79 \\
\hline - Internal Medicine & $37(39.78)$ & $56(60.22)$ & 93 \\
\hline - Oncology & $11(73.33)$ & $4(26.67)$ & 15 \\
\hline - Infectious Disease & $6(26.09)$ & $17(73.91)$ & 23 \\
\hline - General/Family Medicine & $18(72.0)$ & $7(28.0)$ & 25 \\
\hline - Orthopaedics Surgery & $53(42.74)$ & $71(57.26)$ & 124 \\
\hline - Vascular Surgery & $24(60.0)$ & $16(40.0)$ & 40 \\
\hline - General Surgery & $84(38.53)$ & $134(61.47)$ & 218 \\
\hline - Other Surgery & $26(34.67)$ & $49(65.33)$ & 75 \\
\hline \multicolumn{4}{|l|}{ Type of surgery } \\
\hline - Hip replacement & $16(100.00 \%$ & 0 & 16 \\
\hline - Knee replacement & $19(100.00 \%$ & 0 & 19 \\
\hline - Hip fracture & $21(100.00 \%$ & 0 & 21 \\
\hline - Curative arthroscopy & $0(0.00 \%$ & $6(100)$ & 6 \\
\hline - Other Ortho trauma & $1(3.03 \%$ & $32(96.97)$ & 33 \\
\hline - Colon /small bowel & $17(51.52 \%$ & $16(48.48)$ & 33 \\
\hline - Rectosigmoid & $7(63.64 \%$ & $4(36.36)$ & 11 \\
\hline - Gastric & $6(31.58 \%$ & $13(68.42)$ & 19 \\
\hline - Hepatobiliary & $30(45.45 \%$ & $36(54.55)$ & 66 \\
\hline - Vascular & $0(0.00 \%$ & $1(100)$ & 1 \\
\hline - Thoracic & $4(28.57 \%$ & $10(71.43)$ & 14 \\
\hline - Oncologic & $15(78.95 \%$ & $4(21.05)$ & 19 \\
\hline - Others & $60(28.57 \%$ & $150(71.43)$ & 210 \\
\hline
\end{tabular}

ACCP American College of Chest Physicians

overall rate of VTE prophylaxis use in the Middle East among eligible patients was $47.8 \%$ for medical patients and $60 \%$ for surgical patients; while the rate of compliance to ACCP guidelines was only 36\% [22]. Globally, the multinational multicenter IMPROVE study reported that the appropriate use of VTE prophylaxis in eligible medical patients was $60 \%$ [29].

Although the underutilization of VTE prophylaxis in at-risk patients represents a major cause of in-hospital mortality and morbidity, inappropriate use of VTE prophylaxis in low-risk patients, when not medically indicated, can have a negative impact on patients' outcomes leading to bleeding and drugs interaction [30]. In the present study, we found that $77.97 \%$ of the medical patients, who were not eligible for VTE prophylaxis, received prophylactic agents, compared to $66.88 \%$ of the surgical patients who were not eligible for VTE prophylaxis. Similar to our findings, a multicenter study from the United States (US) reported that $77.9 \%$ of hospitalized patients received excessive VTE prophylaxis without appropriate indication [31]. Another retrospective cohort study reported that pharmacological VTE prophylaxis was present in $74 \%$ of low-risk patients, who were not eligible for prophylaxis [30]. 
Table 6 Multivariate logistic regression analysis to identify the significant Predictor Variables for appropriate prophylaxis

\begin{tabular}{lllll}
\hline & OR & \multicolumn{2}{l}{$\mathbf{9 5 \%}$ C.I. for OR } & P value \\
\cline { 3 - 4 } & & Lower & Upper & \\
\hline Age & 1.05 & 1.042 & 1.071 & $<\mathbf{0 . 0 0 1}^{\text {a }}$ \\
Gender & 1.11 & 0.764 & 1.627 & 0.573 \\
BMI & 0.99 & 0.954 & 1.033 & 0.719 \\
SBP & 0.98 & 0.974 & 1.004 & 0.145 \\
DBP & 1.00 & 0.983 & 1.031 & 0.567 \\
HR & 1.01 & 0.994 & 1.027 & 0.226 \\
Temperature & 1.13 & 0.733 & 1.768 & 0.564 \\
Hospital Stay & 1.02 & 0.996 & 1.047 & 0.094 \\
Included hospitals & 0.97 & 0.918 & 1.041 & 0.480 \\
Type of hospital & 1.48 & 0.872 & 2.505 & 0.147 \\
Site of hospitals & 1.23 & 0.986 & 1.558 & 0.066 \\
Medical Reasons & 2.95 & 0.536 & 16.281 & 0.213 \\
Surgical Reasons & 0.68 & 0.125 & 3.771 & 0.664 \\
\hline OR
\end{tabular}

OR Odds ratio, $\mathrm{Cl}$ Confidence interval

aPatients' age is the only significant predictor for appropriate prophylaxis

\section{Conclusion}

In conclusion, the rates of the appropriate use of VTE prophylaxis among hospitalized patients and guideline compliance are low in Lebanon and Jordan. There are wide variations in the rates of the appropriate use of VTE prophylaxis according to the type of hospitals, geographical areas, and the specialty of treating physicians; therefore, awareness campaigns about the appropriate VTE prophylaxis should be performed. Besides, standardized protocols for VTE prophylaxis use for hospitalized patients in both countries should be developed and utilized. Appropriate use of VTE prophylaxis can substantially reduce the costs associated with treating VTE.

\section{Supplementary Information}

The online version contains supplementary material available at https://doi. org/10.1186/s12959-021-00261-2

Additional file 1. STROBE checklist of items that should be included in reports of cross-sectional studies.

Additional file 2. VTE prophylaxis differences according to doctor's specialty and types of surgery.

\section{Abbreviations}

ACCP: American College of Chest Physicians; BMI: Body mass index; Cl: Confidence interval; DVT: Deep venous thrombosis; GCSs: Graduated compression stockings; IPC: Intermittent pneumatic compression; LMWH: Low molecular weight heparin; VTE: Venous thromboembolism; UFH: Unfractionated heparin; US: United States

\section{Acknowledgments}

The authors thank the study participants, trial staff, and investigators for their participation.

\section{Authors' contributions}

$\mathrm{IH}$ developed the study design, shared in data collection, interpreted the data, and revised the manuscript; MA developed the study design, shared in data collection, interpreted the data, and revised the manuscript; KB shared in data collection, analyzed and interpreted the data, and revised the manuscript; MB shared in data collection, analyzed and interpreted the data, and revised the manuscript; $\mathrm{SH}$ shared in data collection, analyzed and interpreted the data, and revised the manuscript; JK shared in data collection and manuscript writing; NS shared in data collection and manuscript writing; CF shared in data collection and manuscript writing. The author(s) read and approved the final manuscript.

\section{Funding}

This study was sponsored and funded by Sanofi. Editorial support was provided by Ahmed Elgebaly MD, of RAY-CRO, and paid for by Sanofi.

Availability of data and materials

Not applicable.

Ethics approval and consent to participate

The study was approved by the responsible ethics committee of health authorities in Jordan and Lebanon. Written informed consent was obtained from every eligible patient, or their relatives, prior to the study's enrollment.

Consent for publication

Not applicable.

Competing interests

The authors declare that they have no competing interests.

\section{Author details}

${ }^{1}$ Department of Surgery, Saint George Hospital University Medical Center, Ashrafiyeh, Beirut, Lebanon. ${ }^{2}$ Department of Surgery, King Hussein Cancer Center, PO Box 1269, Al-Jubeiha, Amman 11941, Jordan. ${ }^{3}$ Department of Special Surgery, Faculty of Medicine, Jordan University of Science and Technology, Ar-Ramtha, Jordan. ${ }^{4}$ Department of General Surgery and Urology, Faculty of Medicine, Jordan University of Science and Technology, King Abdallah University Hospital, Ar-Ramtha, Jordan. ${ }^{5}$ Sanofi, Beirut, Lebanon.

Received: 7 July 2020 Accepted: 1 February 2021

Published online: 10 February 2021

\section{References}

1. Battinelli EM, Murphy DL, Connors JM. Venous Thromboembolism Overview. Hematology/Oncology Clinics of North America; 2012.

2. Martinelli I. Risk factors in venous thromboembolism. In: Thrombosis and Haemostasis; 2001. p. 395-403.

3. Tagalakis $V$, Patenaude $V$, Kahn SR, Suissa $S$. Incidence of and mortality from venous thromboembolism in a real-world population: The Q-VTE study cohort. Am J Med. 2013;126(9):832.e13-21.

4. Scheres $\sqcup J$, Lijfering WM, Cannegieter SC. Current and future burden of venous thrombosis: not simply predictable. Res Pract Thromb Haemost. 2018;2(2):199-208.

5. Henke PK, Pannucci CJ. Venous thromboembolism risk factor assessment and prophylaxis. Phlebology. 2010;25:219-23.

6. Geerts WH, Bergqvist D, Pineo GF, Heit JA, Samama CM, Lassen MR, et al. Prevention of venous thromboembolism: American College of Chest Physicians Evidence-Based Clinical Practice Guidelines (8th edition). Chest. 2008;133(6 Suppl):381S-453S.

7. Cohen AT, Bergmann JF, Lloret-Linares C, Rami A, Garay RP, Kakkar AK, et al. Venous thromboembolism risk and prophylaxis in the acute hospital care setting (ENDORSE study): a multinational cross-sectional study. Lancet. 2008;37:387-94.

8. Heriot GS, Pitman AG, Gonzales M, McKelvie P. The four horsemen: Clinicopathological correlation in 407 hospital autopsies. Intern Med J. 2010;40(9): 626-32.

9. Abdel-Razeq H. Venous thromboembolism prophylaxis for hospitalized medical patients, current status and strategies to improve. Ann Thorac Med. 2010;5(4):195.

10. Liu LT, Ma BT. Prophylaxis against venous thromboembolism in orthopedic surgery. Chin J Traumat. 2006;9(4):249-56.

11. Mismetti P, Laporte-Simitsidis S, Tardy B, Cucherat M, Buchmüller A, JuillardDelsart $D$, et al. Prevention of venous thromboembolism in internal 
medicine with unfractionated or low-molecular-weight heparins: a metaanalysis of randomised clinical trials. Thromb Haemost. 2000;83(1):14-9.

12. Kearon C, Akl EA, Comerota AJ, Prandoni P, Bounameaux H, Goldhaber SZ, et al. Antithrombotic therapy for VIE disease: Antithrombotic therapy and prevention of thrombosis, 9th ed: American College of Chest Physicians evidence-based clinical practice guidelines. Chest. 2012;141(2 SUPPL):2419S-96S [cited 2020 Dec 17]; Available from: https:/pubmed.ncbi.nlm.nih.gov/22315268/.

13. Lloyd NS, Douketis JD, Moinuddin I, Lim W, Crowther MA. Anticoagulant prophylaxis to prevent asymptomatic deep vein thrombosis in hospitalized medical patients: A systematic review and meta-analysis. J Thromb Haemost. 2008;6:405-14.

14. Mokhtari M, Salameh P, Kouchek M, Kashani BS, Taher A, Waked M. The AVAlL ME extension: a multinational middle eastern survey of venous thromboembolism risk and prophylaxis. J Thromb Haemost. 2011;9(7):1340-9.

15. Hammoudeh S, Gadelhak W, Janahi I. Asthma and obesity in the Middle East region: An ovenview. Annals of Thoracic Medicine. 2019;14:116-21 Wolters Kluwer Medknow Publications.

16. Abuyassin B, Laher I. Diabetes epidemic sweeping the Arab world. World J Diabetes. 2016;7(8):165.

17. Hirsh J, Hoak J. Management of deep vein thrombosis and pulmonary embolism: A statement for healthcare professionals. Circulation. 1996;93:2212-45 [cited 2020 Dec 18]; Available from: https:/pubmed.ncbi.nlm.nih.gov/8925592/.

18. Galante M, Languasco A, Gotta D, Bell S, Lancelotti T, Knaze V, et al. Venous thromboprophylaxis in general surgery ward admissions: Strategies for improvement. Int J Qual Heal Care. 2012;24(6):649-56 [cited 2020 Dec 16]; Available from: https//pubmed.ncbi.nlm.nih.gov/22893664/.

19. Zeitoun AA, Dimassi HI, El Kary DY, Akel MG. An evaluation of practice pattern for venous thromboembolism prevention in Lebanese hospitals. J Thromb Thrombolysis. 2009;28(2):192-9.

20. Awidi A, Obeidat N, Magablah A, Bsoul N. Risk stratification for venous thromboembolism in hospitalized patients in a developing country: a prospective study. J Thromb Thrombolysis. 2009;28(3):309-13.

21. Von Elm E, Altman DG, Egger M, Pocock SJ, Gøtzsche PC, Vandenbroucke JP, et al. The strengthening the reporting of observational studies in epidemiology ( STROBE ) statement: guidelines for reporting observational studies *. Int J Surg. 2014;12(12): 1495-9.

22. Taher AT, Aoun J, Salameh P. The AVAIL ME study: a multinational survey of VTE risk and prophylaxis. J Thromb Thrombolysis. 2011;31(1):47-56.

23. Kearon C, Akl EA, Ornelas J, Blaivas A, Jimenez D, Bounameaux H, et al. Antithrombotic therapy for VTE disease: CHEST guideline and expert panel report. Chest. 2016;149(2):315-52.

24. Levine RL, Hergenroeder GW, Miller CC, Davies A. Venous thromboembolism prophylaxis in emergency department admissions. J Hosp Med. 2007;2(2):79-85.

25. Schünemann HJ, Cushman M, Burnett AE, Kahn SR, Beyer-Westendorf J, Spencer FA, et al. American Society of Hematology 2018 guidelines for management of venous thromboembolism: prophylaxis for hospitalized and nonhospitalized medical patients. Blood Adv. 2018;2:3198-225.

26. Gharaibeh L, Albsoul-Younes A, Younes N. Evaluation of venous thromboembolism prophylaxis after the introduction of an institutional guideline: extent of application and implementation of its recommendations. J Vasc Nurs. 2015;33(2):72-8.

27. Abba AA, Al Ghonaim MA, Rufai AM. Physicians' practice for prevention of venous thromboembolism in medical patients. J Coll Physicians Surg Pakistan. 2004;14(4): $211-4$

28. Mokhtari M, Attarian H, Norouzi M, Kouchek M, Kashani BS, Sirati F, et al. Venous thromboembolism risk assessment, prophylaxis practices and interventions for its improvement (AVAlL-ME extension project, Iran). Thromb Res. 2014;133(4):567-73.

29. Tapson VF, Decousus H, Pini M, Chong BH, Froehlich JB, Monreal M, et al. Venous thromboembolism prophylaxis in acutely ill hospitalized medical patients: findings from the international medical prevention registry on venous thromboembolism. Chest. 2007;132(3):936-45.

30. Pavon JM, Sloane RJ, Pieper CF, Colón-Emeric CS, Cohen HJ, Gallagher D, et al. Poor adherence to risk stratification guidelines results in overuse of venous thromboembolism prophylaxis in hospitalized older adults. J Hosp Med. 2018;13(6): 403-4.

31. Grant PJ, Conlon A, Chopra V, Flanders SA. Use of venous thromboembolism prophylaxis in hospitalized patients. JAMA Intern Med. 2018;178(8):1122.

\section{Publisher's Note}

Springer Nature remains neutral with regard to jurisdictional claims in published maps and institutional affiliations.

Ready to submit your research? Choose BMC and benefit from:

- fast, convenient online submission

- thorough peer review by experienced researchers in your field

- rapid publication on acceptance

- support for research data, including large and complex data types

- gold Open Access which fosters wider collaboration and increased citations

- maximum visibility for your research: over $100 \mathrm{M}$ website views per year

At $\mathrm{BMC}$, research is always in progress.

Learn more biomedcentral.com/submissions 